\title{
Fibre sources for the food industry
}

\author{
BY I. T. JOHNSON \\ AFRC Institute of Food Research, Norwich Laboratory, Colney Lane, Norwich NR4 7UA
}

Few issues in human nutrition have captured popular attention in the way that dietary fibre has in recent years. The hypotheses of Burkitt et al. (1972), coupled with the considerable body of new knowledge which has been accumulated over the last decade or so, have led to a general consensus that the consumption of dietary fibre should rise significantly, and there is a very widespread awareness and acceptance of this view amongst consumers. The recommendations of the National Advisory Committee on Nutrition Education (1983) in this context were that average intakes should rise from 20 $\mathrm{g}$ fibre/d to about $30 \mathrm{~g}$ fibre/d (with fibre as defined by the Southgate method (Southgate, 1976)), and that this increase should come largely from high-extraction cereals. Similar, though less precise, recommendations have recently been published in the USA as part of The Surgeon General's Report on Nutrition and Health (1988). As Southgate (1988) has pointed out, it is very difficult to obtain this substantial increase in dietary fibre from a Western mixed diet unless it contains significant quantities of high-extraction cereal products. Such foods must through necessity be highly processed before consumption, and this has created important new marketing opportunities for bread and cereals manufacturers, as a glance at the shelves of any supermarket will confirm.

The original dietary fibre hypothesis was based on epidemiological evidence, and hence on comparisons of total fibre intake amongst populations. This has led to an over-preoccupation with the absolute content of dietary fibre in foods, together with a heated and as yet unresolved debate as to how this absolute content should be defined and measured. The definition of dietary fibre used in the present paper is that of Trowell et al. (1976): 'the sum of lignin and the plant polysaccharides which are not digested by the endogenous secretions of the human gastro-intestinal tract'. It should never be forgotten that all definitions of fibre encompass a range of polysaccharides with different physico-chemical properties and biological effects. The major components of dietary fibre and their principal sources are cell wall components (cellulose, hemicellulose, lignin and pectic substances), non-structural components (gums and mucilages) and industrial additives (modified cellulose, modified pectin, commercial gums and algal polysaccharides). Space does not permit a comprehensive discussion of the chemical and physical properties of the various materials but excellent reviews are available (for example, Selvendran et al. 1987).

It is a fundamental error to assume that any particular material which falls within the definition of fibre and has appropriate functional properties in foods, will automatically be of significant nutritional benefit to the consumer. In the present paper I shall discuss briefly three major physiological effects of fibre, together with the benefits to health with which they are believed to be associated. In each case the appropriate sources of fibre, the relevant foods, and some manufacturing strategies available to the food industry will also be reviewed. 


\section{LAXATIVE PROPERTIES}

The ability of dietary fibre to increase faecal bulk, and hence to reduce both faecal transit time and muscular strain during the passage of stool, was identified by Burkitt \& Trowell (1975) as an important mechanism in the prevention of diseases thought to be associated with chronically increased intra-colonic and intra-abdominal pressure. It remains the most widely recognized property of dietary fibre amongst consumers, many of whom apparently believe themselves to be constipated and in need of laxatives (National Advisory Committee on Nutrition Education, 1983). The use of dietary fibre supplements as a means of managing diverticulosis and haemorrhoids now appears to be widespread amongst gastroenterologists. By no means all components of dietary fibre increase faecal bulk to any significant extent; it is a property primarily of the insoluble and poorly fermentable components of cereal brans. In order to comply with the dietary goal of achieving a significant increase in fibre intake from foods rather than from non-culinary supplements, the fibre must be consumed in products which form a regular and substantial proportion of conventional Western diets. Bread and breakfast cereals are the obvious candidates for this role, as food manufacturers have been quick to realize.

Wheat bran is a widely used source of dietary fibre. It has long been accepted as a bulk laxative (Cowgill \& Anderson, 1932) and has proven value in the management of large-bowel disorders (Findlay et al. 1974; Taylor \& Duthie, 1976). It is a traditional ingredient which is widely accepted by consumers, and consumption of wholemeal bread and wheat bran-based breakfast cereals has risen substantially in recent years. Wholewheat bread contains about $85 \mathrm{~g}$ dietary fibre $/ \mathrm{kg}$ compared with approximately $25 \mathrm{~g} / \mathrm{kg}$ in a typical white bread. However, the whole-wheat product has characteristic qualities of texture, colour and flavour which tend to limit its appeal, and this has led food technologists to seek alternative bread formulations and sources of fibre.

Purified $\alpha$-cellulose prepared from wood-pulp is virtually $100 \%$ dietary fibre, of which about $90 \%$ is $\beta-1,4-$ glucan. This material can be used to prepare high-fibre breads with a dietary fibre content three or four times higher than that of conventional products, but because the cellulose modifies the dough characteristics of the bread it is necessary to add increased levels of gluten and to modify the fat and moisture contents to achieve an acceptable texture.

Purified cellulose is poorly fermented by the colonic microflora of both the rat and man (Van Soest, 1984). In the rat there is an approximately linear relationship between both wet and dry faecal bulk and dietary intake of cellulose over a nutritionally significant range. In Fig. 1 this is illustrated by the wet weights and dry weights of faeces divided by food intakes of rats fed on a fibre-free diet or on a diet containing cellulose $(100 \mathrm{~g} / \mathrm{kg})$ as Solka Floc. Wheat bran contains less than half the dietary fibre of Solka Floc. However, in Fig. 1 the corrected wet weight of faeces produced by animals fed on $100 \mathrm{~g}$ wheat bran $/ \mathrm{kg}$ lies above the cellulose line when plotted at the appropriate level of dietary non-starch polysaccharide. The reasons for this are not clear but the undigested wheat bran particles may have a higher water-holding capacity because of their larger size (Cadden, 1986), and possibly because of their arabinoxylan content. Purified cellulose is known to increase faecal bulk to some extent in man (Hillman et al. 1983), but there have been relatively few studies, and nothing is known of its long-term effect on health. Its use in foods is banned in some countries and alternative high-fibre materials for use in foods have, therefore, been sought. 


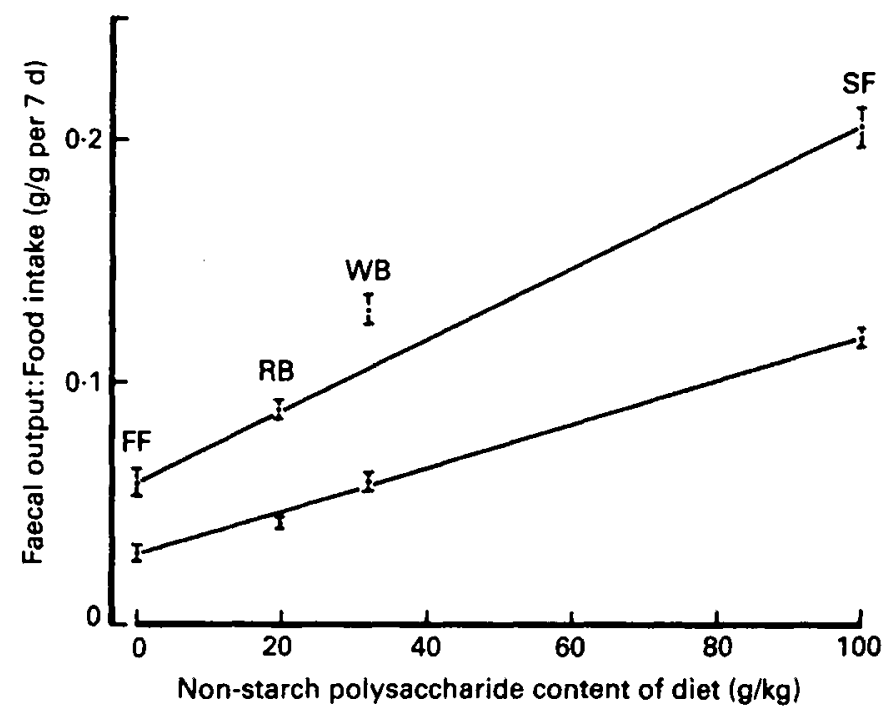

Fig. 1. The mean wet weight (upper line) and dry weight (lower line) of faeces/food intake of rats $v$. non-starch polysaccharide content of semi-synthetic diets. Apart from the fibre-free diet (FF) the diets contained rice bran (RB), wheat bran (WB) or cellulose as Solka Floc (SF) at a concentration of $100 \mathrm{~g} / \mathrm{kg}$ dry weight. Each point is the mean value, with standard errors represented by vertical bars, for five pairs of rats (Johnson et al. 1989).

Amongst the materials which have been successfully incorporated into experimental bread formulations are field pea (Pisum arvense) hulls, maize bran and wild oat (Avena sativa) bran (Sosulski \& Wu, 1988), as well as flax (Linum usitatissimum) and sunflower (Helianthus annus) hulls (Cadden et al. 1983). The latter materials had adverse effects on the quality of the bread, but pea and maize fibre can be used to prepare breads of acceptable quality with total dietary fibre contents of 150 and $210 \mathrm{~g} / \mathrm{kg}$ dry weight respectively, compared with $40 \mathrm{~g} / \mathrm{kg}$ for a comparable white bread (Sosulski \& Wu, 1988). Pea hulls enhance faecal output in rats significantly, but their nutritional effects in man do not appear to have been fully evaluated.

Sugar-beet fibre and rice bran are examples of materials derived as by-products of raw-material processing, which can be made into versatile and palatable sources of dietary fibre by the application of food technology. With the thermal processing techniques such as extrusion cooking, or par-boiling of rice before milling (James \& Sloan, 1984), rice bran can be stabilized to prevent the development of rancidity, and incorporated into breads and other products (Babcock, 1987). Fig. 1 indicates that the faecal bulking properties of rice bran are similar to those of wheat bran in the rat. However, recent studies with human volunteers suggest that dietary supplements of rice bran are slightly more effective than wheat bran as a means of increasing the output of stool and decreasing the faecal transit time (Tomlin \& Read, 1988).

Apart from breads, breakfast cereals naturally lend themselves to the incorporation of dietary fibre in significant quantities. The use of whole grains in the formulation of breakfast cereals leads to products containing 2-3 g dietary fibre per serving, whilst the incorporation of wheat or maize bran can be used to prepare products containing up to 9 g per serving. 
The effect of particular processing techniques on the biological properties of dietary fibre must be taken into account in product development. For example, particle size is known to influence the faecal bulking properties of wheat bran (Heller et al. 1980; Cadden, 1986). Extrusion cooking of wheat products leads to a redistribution of fibre from insoluble to soluble fractions (Bjorck et al. 1984). The choice and processing of particular materials for individual products is a matter for the food technologists, but their biological effects and suitability in relation to nutritional needs must be judged from the relevant scientific literature, or ideally from physiological studies in human subjects, using the particular product in question.

\section{HYPOCHOLESTEROLAEMIC EFFECTS}

Traditional diets amongst population groups with a low risk of coronary heart disease tend to be high in available carbohydrates and dietary fibre and low in fat (Keys, 1970). Recent epidemiological studies suggest an inverse correlation between the intake of fibre and the incidence of coronary heart disease in Western populations (Kushi et al. 1985). The mechanism of action is poorly understood, but the effect is probably partly due to a low intake of dietary fat and a consequent favourable plasma lipid profile. There is also a significant body of experimental work indicating that some components of dietary fibre have an independent hypocholesterolaemic effect, but it is important to realize that this is confined to water-soluble fractions. Plant gums which have been shown to reduce plasma cholesterol levels in man when given as a dietary supplement include the viscous storage polysaccharides guar gum (Jenkins et al. 1980) and locust bean gum (Ceratonia siliqua) (Zavorai et al. 1983), pectin from various sources (Judd \& Truswell, 1982), and to a small extent gum arabic, which is an exudate gum with a low viscosity (Ross et al. 1983). Other materials of potential commercial importance include the $\beta$-glucan constituents of oat bran and as yet unidentified components of certain legumes (Anderson et al. 1984). Modified cellulose gums such as sodium carboxymethylcellulose (CMC) do not appear to reduce plasma cholesterol levels in man, but unlike the fermentable gums mentioned previously, they do increase faecal bulk in human subjects (Anderson et al. 1986).

Some of the highly viscous and physiologically active water-soluble gums are widely used in the food industry as a means of modifying texture in manufactured food products, but the intake of dietary fibre from such existing applications is negligible. Apart from their use in the specialized pharmaceutical products mentioned later, it is unlikely that the high-viscosity polysaccharides can be used to enrich foods to a nutritionally significant extent.

Low-viscosity polysaccharides on the other hand lend themselves much more readily to incorporation into a variety of food products, particularly beverages, soft drinks and soups, where they can often be used to replace starch as a thickener. It has been pointed out, for example, that in a typical soup containing $40 \mathrm{~g}$ starch $/ \mathrm{kg}, 20 \mathrm{~g}$ can be replaced by a mixture of low-viscosity guar gum and $\mathrm{CMC}$, to achieve a dietary fibre content close to $2 \%$, with no detectable alteration in the rheological characteristics (Andon, 1987). It seems unlikely that such foods alone could be used to achieve a prolonged and physiologically significant increase in soluble fibre intake from an otherwise acceptable mixed diet, but in combination with legumes or other complex carbohydrate foods a clinically significant reduction in plasma cholesterol levels might be achieved. 
In the previously mentioned context, oat products might provide a particularly important opportunity for new product development. Oat bran contains $\beta$-glucan, an unbranched, high-molecular-weight polysaccharide which develops a high viscosity in water and has a significant hypocholesterolaemic action in both experimental animals and man (Anderson et al. 1984). Recent reports from the USA indicate that less than $20 \mathrm{~g}$ oat bran/d can significantly reduce serum total cholesterol levels in young, healthy volunteers (Gold \& Davidson, 1988). Moreover, the reduction occurred primarily in the low-density-lipoprotein-cholesterol subfraction which is believed to be an important factor in relation to coronary heart disease. Another recent paper suggests that oat bran may be a highly cost-effective alternative to pharmacological intervention as a means of reducing plasma cholesterol in individuals with abnormal cholesterol levels (Kinosian \& Eisenberg, 1988). The incorporation of this material into palatable foods for long-term use in mixed diets, therefore, poses an important new opportunity for food manufacturers.

\section{HYPOGLYCAEMIC EFFECTS}

The usefulness of diets rich in dietary fibre in the management of diabetes melitus has been demonstrated by Anderson \& Ward (1979) in the USA, and by Mann's group in the UK (Simpson et al. 1981). A considerable amount of work has been done on the physiological effects of various components of dietary fibre in the small intestine and their effect on the absorption and metabolism of glucose from carbohydrate foods (Jenkins et al. 1978; Johnson, 1984). Two mechanisms seem to be important. Soluble polysaccharides with a high viscosity increase the resistance to diffusion of nutrients within the lumen of the small intestine, and hence slow the movement of glucose through the boundary layer at the mucosal surface (Johnson \& Gee, 1981; Edwards et al. 1988). This delays the uptake of carbohydrate and leads to a reduced rate of entry into the circulation (Blackburn et al. 1984). Second, the digestion of complex carbohydrate foods such as legumes is considerably slower than that of bread, rice or potatoes (Gee \& Johnson, 1985). This appears to be due to the survival of intact cell walls, which enclose the starch granules in the cooked material, rather than, as is often assumed, to the presence of viscous polysaccharides (Wursch et al. 1986).

Two strategies are available for the exploitation of these effects in foods designed to elicit a relatively low blood glucose response in diabetics and others. The first is to incorporate highly viscous polysaccharides such as guar gum into carbohydrate foods. To be effective the foods must contribute a major proportion of the daily carbohydrate intake and bread is, therefore, the obvious candidate. Jenkins' studies in the 1970 s were carried out with breads containing about $1 \mathrm{~g}$ guar gum per slice (Apling et al. 1977). Apling \& Ellis (1982) subsequently developed a palatable, soft, guar gum bread. Other starchy foods such as pasta (Gatti et al. 1984) and biscuits (Ellis et al. 1988) also lend themselves to the incorporation of viscous polysaccharides, but they inevitably have distinctive texture and flavour characteristics which may make them unacceptable for general use.

The second approach is to try to preserve, in finished products, the inherent low digestibility of some high-fibre, complex carbohydrate foods. The presence of intact cell walls enclosing ungelatinized starch granules is associated with dietary fibre in plant foods, but their existence cannot be quantified by chemical analysis alone, even 
though the slow release of glucose can be observed in human subjects (Haber et al. 1977), and measured in vitro (Gee \& Johnson, 1985). As might be expected, the use of extreme processing conditions seems to destroy this property. The blood glucose response to extruded or otherwise thermally processed potato and maize snacks is significantly higher than to conventionally cooked equivalents (Brand et al. 1985). Interestingly, there is a small increase in the total dietary fibre content of extrusion-cooked wheat flour, and some redistribution of dietary fibre from insoluble to soluble fractions (Bjorck et al. 1984).

The difficulty of preserving the intrinsic cellular structure of complex carbohydrates in manufactured foods may perhaps be circumvented by the use of food-manufacturing technology. Retrogradation of starch in thermally processed foods gives rise to a fraction which resists digestion by small-intestinal enzymes (Berry, 1986; Ring et al. 1988). The issue of whether or not this resistant starch fraction should or should not be classified as dietary fibre will not be raised here. The more interesting question is whether the material has biological effects which are similar to those of dietary fibre and can usefully be exploited in manufactured foods. Thermally processed high-amylose starches may have many of the properties which are associated with cell wall polysaccharicles in 'whole' or unprocessed foods, but a substantial amount of further research will be needed to test this possibility.

To conclude, the impact of the dietary fibre hypothesis presents the food industry with both challenges and opportunities. There is little doubt that food technology can be used to make dietary fibre available to the consumer in a variety of new and palatable forms. However, the design of such products should not be based on the simple goal of achieving the highest possible fibre content from the cheapest possible source. If the consumer is to experience real nutritional benefits, it is essential that the use of processed fibre sources should be matched with a knowledge of their physiological effects.

\section{REFERENCES}

Anderson, D. M. W., Eastwood, M. A. \& Brydon, W. G. (1986). The dietary effects of sodium carboxymethylcellulose in man. Food Hydrocolloids 1, 37-44.

Anderson, J. W., Story, L., Sieling, B., Chen, W. L., Petro, M. S. \& Story, J. (1984). Hypocholesterolemic effects of oat-bran or bean intake for hypercholesterolemic men. American Journal of Clinical Nutrition $\mathbf{4 0}$, 1146-1155.

Anderson, J. W. \& Ward, K. (1979). High carbohydrate, high fiber diets for insulin treated men with cliabetes mellitus. American Journal of Clinical Nutrition 32, 2312-2321.

Andon, S. A. (1987). Applications of soluble dietary fibre. Food Technology, January, 74-75.

Apling, E. C. \& Ellis, P. R. (1982). Guar bread: concept to application. Chemistry \& Industry, December, 950-954.

Apling, E. C., Leeds, A. R., Wolever, T. M. S. \& Jenkins, D. J. A. (1977). How to make guar bread. Lancet ii, 975.

Babcock, D. (1987). Rice bran as a source of dietary fibre. Cereal Foods World 32, 538-539.

Berry, C. S. (1986). Resistant starch: formation and measurement of starch that survives exhaustive digestion with amylolytic enzymes during the determination of dietary fibre. Journal of Cereal Science 4, 301-314.

Bjorck, I., Nyman, M. \& Asp, N.-G. (1984). Extrusion cooking and dietary fibre: effects on dietary fibre content and on degradation in the rat intestinal tract. Cereal Chemistry 61, 174-179.

Blackburn, N. A., Redfern, J. S., Jarjis, H., Holgate, A. M., Hanning, I., Scarpello, J. H. B., Johnson. I. T. \& Read, N. W. (1984). The mechanism of action of guar gum in improving glucose tolerance in man. Clinical Science 66, 329-336.

Brand, J. C., Nicholson, P. L., Thorburn, A. W. \& Truswell, A. S. (1985). Food processing and the glycaemic index. American Journal of Clinical Nutrition 42, 1192-1196. 
Burkitt, D. P. \& Trowell, H. C. (1975). Refined Carbohydrate Foods and Disease: Some Implications of Dietary Fibre. London: Academic Press.

Burkitt, D. P., Walker, A. R. P. \& Painter, N. S. (1972). Effect of dietary fibre on stools and transit times and its role in the causation of disease. Lancet ii, 1408-1412.

Cadden, A. M. (1986). Effects of particle size and breadmaking on physiological responses of meal-fed rats to AACC wheat bran. Journal of Food Science 51, 188-192.

Cadden, A. M., Sosulski, F. W. \& Olson, J. P. (1983). Physiological responses of rats to high fibre bread diets containing several sources of hulls or bran. Journal of Food Science 48, 1151-1156.

Cowgill, G. R. \& Anderson, W. E. (1932). Laxative effects of wheat bran and 'washed bran' in healthy men. A comparative study. Journal of the American Medical Association 98, 1866-1875.

Edwards, C. A., Johnson, I. T. \& Read, N. W. (1988). Do viscous polysaccharides slow absorption by inhibiting diffusion or convection? European Journal of Clinical Nutrition 42, 307-312.

Ellis, P. R., Kamalanathan, T., Dawoud, F. M., Strange, R. N. \& Coultate, T. P. (1988). Evaluation of guar biscuits for use in the management of diabetes: Tests of physiological effects and palatability in non-diabetic volunteers. European Journal of Clinical Nutrition 42, 425-435.

Findlay, J. M., Mitchell, W. D., Smith, A. N., Anderson, A. J. B. \& Eastwood, M. A. (1974). Effects of unprocessed wheat bran on colonic function in normal subjects and in diverticular disease. Lancet $\mathbf{i}$, $146-149$.

Gatti, E., Catenazzo, G., Camisasca, E., Torri, A., Denegri, E. \& Sirtori, C. R. (1984). Effects of guar-enriched pasta in the treatment of diabetes and hyperlipidemia. Annals of Nutrition and Metabolism 28, $1-10$.

Gee, J. M. \& Johnson, I. T. (1985). Rates of starch hydrolysis and changes in viscosity in a range of common foods subjected to simulated digestion in vitro. Journal of the Science of Food and Agriculture 36, 614-620.

Gold, K. V. \& Davidson, D. M. (1988). Oat bran as a cholesterol-reducing dietary adjunct in a young healthy population. Western Journal of Medicine 148, 299-302.

Haber, G. B., Heaton, K. W., Murphy, D. \& Burroughs, L. F. (1977). Depletion and disruption of dietary fibre: effects on satiety, plasma glucose, and serum-insulin. Lancet ii, 679-682.

Heller, S. N., Hackler, L. R., Rivers, J. M., Van Soest, P. J., Roe, D. A., Lewis, B. A. \& Robertson, J. (1980). Dietary fibre: the effect of particle size of wheat bran on colonic function in young adult men. American Journal of Clinical Nutrition 33, 1734-1744.

Hillman, L., Peters, S., Fisher, A. \& Pomare, E. W. (1983). Differing effects of pectin, cellulose and lignin on stool pH, transit time and weight. British Journal of Nutrition 50, 189-195.

James, C. \& Sloan, S. (1984). Functional properties of edible rice bran in model systems. Journal of Food Science 49, 311.

Jenkins, D. J. A., Reynolds, D., Slavin, B., Leeds, A. R., Jenkins, S. L. \& Jepson, E. M. (1980). Dietary fibre and blood lipids: treatment of hypercholesterolaemia with guar crispbread. American Journal of Clinical Nutrition 33, 575-581.

Jenkins, D. J. A., Wolever, T. M. S., Leeds, A. R., Gassull, M. A., Haisman, P., Dilawari, J., Goff, D. U., Metz, G. L. \& Alberti, K. G. M. M. (1978). Dietary fibres, fibre analogues and glucose tolerance: importance of viscosity. British Medical Journal i, 1392-1394.

Johnson, I. T. (1984). Fibre-how and why it works. In Dietary Fibre in the Management of the Diabetic, pp. 21-25. Oxford: Medical Education Services Ltd.

Johnson, I. T. \& Gee, J. M. (1981). The effect of gel-forming gums on the intestinal unstirred layer and sugar transport in vitro. Gut 22, 398-403.

Johnson, I. T., Gee, J. M. \& Brown, J. C. (1989). A comparison of rice bran, wheat bran and cellulose as sources of dietary fibre in the rat. Food Sciences and Nutrition 42F, 153-163.

Judd, P. A. \& Truswell, A. S. (1982). Comparison of the effects of high and low methoxy pectins on blood and faecal lipids in man. British Journal of Nutrition $48,451-458$.

Keys, A. (1970). Coronary heart disease in seven countries. Circulation 41, Suppl. 1.

Kinosian, B. P. \& Eisenberg, J. M. (1988). Cutting into cholesterol. Cost-effective alternatives for treating hypercholesterolemia. Journal of the American Medical Association 259, 2249-2254.

Kushi, L. H., Lew, R. A., Stare, F. J., Ellison, C. R., Lozy, M., Bourke, G., Daly, L., Graham, I., Hickey, N., Mulcahy, R. \& Kevaney, J. (1985). Diet and 20-year mortality from coronary heart disease. The Ireland-Boston Diet-Heart Study. New England Journal of Medicine 312, 811-818.

National Advisory Committee on Nutrition Education (1983). Proposals for Nutritional Guidelines for Health Education in Britain. London: Health Education Council. 
Ring, S. G., Gee, J. M., Whittam, M., Orford, P. \& Johnson, I. T. (1988). Resistant starch: its chemical form in foodstuffs and effect on digestibility in vitro. Food Chemistry 28, 97-109.

Ross, A. H. M., Eastwood, M. A., Brydon, W. G., Anderson, J. R. \& Anderson, D. M. W. (1983). A study of the effects of dietary gum arabic in humans. American Journal of Clinical Nutrition 37, 368-375.

Selvendran, R. R., Stevens, B. J. H. \& DuPont, M. S. (1987). Dietary fibre: chemistry, analysis and properties. Advances in Food Research 31, 117-209.

Simpson, H. C. R., Lousley, S., Geekie, M., Simpson, R. W., Carter, R. D., Hockaday, T. D. R. \& Mann, J. I. (1981). A high carbohydrate leguminous fibre diet improves all aspects of diabetic control. Lancet $\mathbf{i}$, 1-5.

Sosulski, F. W. \& Wu, K. K. (1988). High-fibre breads containing field pea hulls, wheat, corn and wild oat brans. Cereal Chemistry 65, 186-191.

Southgate, D. A. T. (1976). Determination of Food Carbohydrates. London: Applied Science Publishers.

Southgate, D. A. T. (1988). Dietary fibre and the diseases of affluence. In A Balanced Diet?, pp. 117-141 [J. Dobbing, editor]. London: Springer Verlag.

Taylor, I. \& Duthie, H. L. (1976). Bran tablets and diverticular disease. British Medical Journal i, 988-990.

The Surgeon General's Report on Nutrition and Health (1988). US Department of Health and Human Services, Public Health Service Publication no. 88-50210, Washington, DC: Department of Health and Human Services.

Tomlin, J. \& Read, N. W. (1988). Comparison of the effects on colonic function caused by feeding rice bran and wheat bran. European Journal of Clinical Nutrition 42, 857-861.

Trowell, H., Southgate, D. A. T., Wolever, I. M. S., Leeds, A. R., Gassull, M. A. \& Jenkins, D. J. A. (1976). Dietary fibre redefined. Lancet i, 967.

Van Soest, P. J. (1984). Some physical characteristics of dietary fibres and their influence on the microbial ecology of the human colon. Proceedings of the Nutrition Society 43, 25-33.

Wursch, P., Vedovo, S. D. \& Koellreutter, B. (1986). Cell structure and starch nature as key determinants of the digestion rate of starch in legume. American Journal of Clinical Nutrition 43, 25-29.

Zavorai, J. H., Hannan, P., Fields, D. J., Hanson, M. N., Frantz, I. D., Kuba, K., Elmer, P. \& Jacobs, D. R. (1983). The hypolipidemic effect of locust bean gum food products in familial hypercholesterolaemic adults and children. American Journal of Clinical Nutrition 38, 285-294. 